(c) 2008 CORNELL UNIVERSITY

DOI: $10.1177 / 1938965508322768$

Volume 49, Issue $3 \quad 297-309$

\title{
The Role of Technology in \\ Restaurant Revenue Management
}

by SHERYL E. KIMES

Technology systems can support restaurant managers' efforts to improve sales and profits through revenue management. By subdividing a meal into its component sections, a manager can determine which systems to apply at a particular stage for the purpose of providing the greatest revenue benefit for a particular restaurant. In adopting technology, managers must first conduct a financial analysis to determine whether the technology's cost will be more than offset by revenue improvements. If that financial calculation is favorable, management must then consider benefits to both employees and customers and must also take into account employees' and customers' perceptions of the technology's utility and ease of use. Without those elements in place, the technology faces dim prospects no matter what its prospective financial benefit.
Keywords: restaurant management; revenue management; table management systems; kitchen display systems; handheld ordering systems ppropriate technology, when used in conjunc-
tion with revenue management principles,
can help restaurants of all types increase rev-
enue and profit. In the United States alone, table ser-
vice restaurants account for approximately $\$ 180$
billion per year in revenue (National Restaurant
Association 2006). If these table service restaurants
can achieve the 2 to 5 percent revenue improvement
typically associated with the adoption of revenue
management (Hanks, Noland, and Cross 1992; 
Smith, Leimkuhler, and Darrow 1992; Kimes 2004a), overall revenue could increase by $\$ 3.6$ billion to $\$ 9.0$ billion per year. Correctly implemented, technology can more than offset its cost with increased revenue. Technologies that support restaurant revenue management range from relatively simple credit card processing systems to elaborate table management and kitchen production software.

In this article, I discuss how restaurants can apply technology to the dining experience and achieve both increased profits and customer satisfaction. Focusing chiefly on table-service restaurants, I first provide an overview of revenue management with a particular emphasis on the customer dining experience. I then discuss the benefits of using technology for both customers and restaurants and review how technology can be used in each phase of the dining experience. I conclude with an overview of issues that must be addressed for successful application of technology to the dining experience. The intent of this article is to provide a framework for assessing the effect of technology on meal duration and restaurant revenue.

\section{Revenue Management}

Revenue management has been widely adopted in the airline, hotel, and rental car industries (Carroll and Grimes 1995; Hanks, Noland, and Cross 1992; Smith, Leimkuhler, and Darrow 1992) but has only gained attention in the restaurant industry in the past ten years (Kimes et al. 1998; Kimes 2004a, 2004b; Kimes and Thompson 2004, 2005). Companies using revenue management have reported revenue increases of 2 to 5 percent (Hanks, Noland, and Cross 1992; Kimes 2004a; Smith, Leimkuhler, and Darrow 1992).

Revenue management is activated by the following two strategic levers: duration control and pricing (Kimes and Chase
1998; Kimes et al. 1998). Duration management requires control and knowledge of when customers arrive, how long they stay, and when the table becomes available for the next party. If meal duration can be reduced during busy periods, more customers can be served and revenue can be increased. At the same time, however, duration control must be approached carefully because rushing customers may impair their satisfaction. The duration of a meal, which includes the entire time that the table is in use, can be managed by controlling guest arrival, meal duration, and table turnover.

Managing guest arrivals requires the ability to predict when customers will arrive. Restaurants can manage arrivals both internally (by means that do not directly involve customers) and externally (by mechanism that do directly involve customers). Common internal arrivalmanagement strategies include improving the accuracy of arrival forecasts, tightly managing the customers' waiting times, developing overbooking policies that maximize table use but minimize delayed or denied seating, and setting strategy for how and where parties should be seated. External arrival techniques include reminding customers of their reservations by phone or e-mail, or requiring deposits or guarantees on reservations.

The objective of duration management is to reduce variability in customer dining times and, if necessary, to reduce the length of the meal. Like arrival management, duration can be managed both internally and externally. Internal approaches revolve around streamlining the service process (including ordering, meal preparation, and check delivery and processing), while external approaches include giving customers control over the pace of their meal and giving them signals that the meal is nearing an end. 
Turnover management involves reducing the amount of time between the end of one party's meal and the beginning of the next. Anything that can be done to reduce turnover time and speed the process (either by notifying bussers that it is time to clear the table or letting hosts and hostesses know that the table is ready) should increase revenue during busy periods.

While price management is extremely important to the success of revenue management, the focus of this article is on how technology can be applied to better manage the duration of customer's meals, increase revenue, and increase customer satisfaction.

\section{The Dining Experience}

The customer dining experience consists of six main components (see Exhibit $1)$ :

1. Prearrival: from when customers decide they want to come to the restaurant until they arrive at the restaurant

2. Postarrival: from when customers arrive at the restaurant to when they are seated

3. Preprocess: from when customers are seated at the restaurant until they receive their first food order

4. In-process: from when they receive their order until they request payment

5. Postprocess: from when they request payment until they leave the restaurant

6. Table turnover: from when customers leave until the table is reseated

Studies have been conducted on how long customers think dinner should last (Kimes, Wirtz, and Noone 2002) and on the impact of pace on customer satisfaction (Noone and Kimes 2005; Noone et al. 2007). Looking at the effect of pace, customers' reaction to changes in pacing varies according to the stage of the meal and the type of restaurant. In casual and upscale casual restaurants, customers prefer a faster pace during the preprocess and postprocess stages but a slower pace during the in-process stage (when they are actually dining). Customers at fine-dining restaurants prefer a relatively slow pace throughout the meal (Noone and Kimes 2005; Noone et al. 2007).

Based on this research, restaurant managers should (1) focus their durationreduction efforts on the postprocess stage, (2) consider ways to reduce duration during the preprocess stage, (3) avoid duration-reduction strategies during the in-process stage, (4) consider giving customers control over the pace of their meal, and (5) recognize the importance of maintaining a consistent pace throughout the meal (Noone and Kimes 2005).

\section{Technology and the}

\section{Dining Experience}

Technology comes at a cost, but it can also lead to increased revenue and profit. Before adopting a particular technological system, a restaurant operator must assess potential benefits to customers and to the restaurant and compare these benefits to the cost of the system. Potential customer benefits are improved customer convenience and increased control, while potential benefits to the restaurant are increased speed of service, reduced processing costs, increased volume and revenue, and improved service and food quality.

\section{Benefits to Customers}

Improved convenience. Service convenience is related to customers' desire to conserve their time and effort. An increase in convenience is associated with an increase in satisfaction (Berry, Seiders, and Grewal 2002). Restaurants can use technology to 
increase access convenience (by making it easier for to place a food order or make a reservation), transaction convenience (by reducing customers' waiting time), and benefit convenience (by better managing the pace of the dining experience).

Increased control. When customers perceive that they have substantial control over a service encounter, they are more likely to be satisfied with that encounter (Averill 1973; Hui and Bateson 1991; Hui and Tse 1996; Langer 1983). The following three types of perceived control have been proposed: behavioral, cognitive, and decisional (Averill 1973).

Customers have behavioral control when they can directly influence or modify what happens to them (Hui and Bateson 1991). In restaurants, customers can exert behavioral control by choosing the time they eat, by minimizing their wait, or by choosing their desired table.

Cognitive control is related to the predictability and interpretability of a situation. Research has shown that providing guests with supplemental information (such as the likely length of their wait) leads to a more positive evaluation of the service. If restaurants can provide accurate wait time estimates, they will give customers heightened cognitive control.

Finally, decision control concerns the control that a customer has over the selection of outcomes and goals. For example, in restaurants, customers who have to wait to be seated can choose to stay at the restaurant, leave and return, or just leave and find other dining options. Paging systems give customers more decisional control because in many cases (particularly with cell phone pagers), customers have the freedom to leave the restaurant and return after being paged that their table is ready.

\section{Benefits to the Restaurant}

Service speed. In general, if service speed can be accelerated, more customers can be served. Depending on the stage of the meal, customer satisfaction can be enhanced by increased service velocity, as should revenue (at least during periods of high demand). As a simple example of a seemingly small reduction in service time, a restaurant that could serve 400 customers in its 4-hour rush period would earn $\$ 4,000$ if it had a $\$ 10$ average check, 100 seats, and a 1-hour turnaround. If the average dining time could be reduced by 5 minutes to 55 minutes, the potential number of customers served would increase to 436 ( 240 minutes/55 minutes $\times$ 100 seats) and the potential revenue would increase to $\$ 4,360$, an increase of 9 percent. Of course, this estimate is theoretical. As discussed in an article elsewhere in this issue (Thompson 2008), a simulation of actual revenue increases from a reduction in dining duration demonstrates an increase of about 25 percent of this estimated amount. That said, a 2.25 percent increase in revenue is still substantial.

Technology can speed service by reducing the order-taking time (through the use of preorders or handheld devices), advancing food production (through the use of kitchen display systems), tightening service time (through the use of table management systems, or TMSs), shortening payment time (through handheld devices), and cutting turnaround time (through the use of communications technology and TMSs). While faster service will almost always lead to improved customer satisfaction in quickservice restaurants and fast casual restaurants, it must be managed carefully in casual, upscale casual, and fine dining restaurants, so that customers do not feel that they are being rushed (Noone and Kimes 2005; Noone et al. 2007). 
Reduced processing cost. Technology can also help to reduce labor costs. When online and off-site reservations and orders are taken or when kiosks and other selfservice approaches are used to assist with ordering and payment, labor costs for reservations and order-receiving functions will decrease.

Increased volume and revenue. Making the restaurant more accessible to customers, whether through online reservations or ordering, will attract more customers and result in higher revenue. More than half (59 percent) of restaurants using online reservations and online ordering have seen sales increase as a result (Lang 2006). An important benefit here is that many online reservations are made during periods when restaurants are not normally open (Layton 2006; Ross 2006), which means that the restaurant is most likely capturing business it might not otherwise receive.

Improved service and product quality. Appropriate use of technology can also help a restaurant provide better and more consistent service to its guests. Research has shown that an increase in perceived service and product quality leads to an increase in customer satisfaction and profit (Rust, Zahorik, and Keiningham 1998). Table management and communications systems can help restaurant operators provide more consistent service to guests and can also help improve managerial control of the meal experience.

\section{The Role of Technology} in the Dining Experience

Depending upon the stage of the meal, different types of technology can be employed to help manage the customer dining experience (see Exhibit 2). For example, in the prearrival stage, online reservations and online food ordering can be used to increase access convenience and reduce the amount of time customers must spend at the restaurant. I discuss the technology for each stage of the dining experience below.

\section{Prearrival Stage}

During this stage, restaurant operators should focus on making it easier for customers to order their food or make a reservation, depending on the type of restaurant. While this almost goes without saying, I must point out that any technology adopted for this phase should be integrated with current computer systems so that any necessary information (such as a reservation or food order) can be transferred to the appropriate system and persons.

Preordering. Preordering of food (whether done online or over the phone) gives customers more control over their time by allowing them to select their food before arriving at the restaurant. Online ordering helps restaurants by providing an additional distribution channel (customers may order just because it is easier), provides more opportunities for consistent upselling, and gives restaurants the opportunity to streamline production since they have time to prepare the food before customers arrive at the restaurant-regardless of whether they dine in or take their food out. Obviously, to work well, these systems need to be tightly integrated with the point-of-service (POS) system so that the order is ready at the specified time (Webb 2006).

Online ordering systems have been growing in popularity. In a survey of casual and fine dining restaurants, Lang (2006) found that 38 percent of the restaurants surveyed take food orders online. Websites that offer online ordering include Webfood.com, waiter.com, delivery.com, and foodjr.com. 
Certain casual restaurants, Outback and Applebees, for example, have implemented curbside service, which allows customers to call and place their order for curbside pickup at a specified time. Approximately 10 percent of casual restaurant sales come from curbside service (Krummert 2003; Hellmich 2005; Warner 2006). Curbside service allows restaurants to prepare orders ahead of time but, if not properly managed, can cause undue load on the kitchen. A variety of curbside applications are available including those provided by Long Range Systems, Techknow, and QTime Solutions.

\section{Reservations}

Most fine-dining restaurants and about one-third of casual restaurants take reservations (Kimes and Wirtz 2007), traditionally handled by an employee at the restaurant. That familiar approach maintains the personal touch, but it is sometimes inconvenient for customers because someone is not always at the restaurant, it can be difficult getting through at times, and the person answering the phone is not always trained appropriately. Technology can be used to facilitate online reservations and to provide electronic management of reservations.

Online reservations. Such sites as opentable.com, dinnerbroker.com, guestbridge.com, and restaurantrow.com offer free online reservations for customers. Online reservations allow customers to quickly make a reservation at unfamiliar restaurants (Layton 2006) and also to make a reservation whenever they would like. (Opentable.com estimates that 25 percent of reservations are made between 10:00 p.m. and 10:00 a.m., hours that restaurants are not typically open). In addition, online reservations give restaurants an additional distribution channel (for example, OpenTable estimates that 50 percent of its reservations are incremental reservations [Randall Reeves, personal communication, 2007]) and provides the restaurant with no-show data, marketing opportunities, and in some cases an electronic reservations book and a TMS.

Other reservations systems. Another approach to automating the reservation process allows restaurant operators to create an electronic reservation book. Companies that support this approach, including JTech (HostAlert) and NTN (ProHost), provide software either for reservations or for call-ahead seating. When customers contact the restaurant or a call center to make their reservation, the restaurants can track reservations and availability and also collect additional guest history information (such as special events such as birthdays and anniversaries, seating preferences, food preferences, and no-show history).

\section{Postarrival Stage}

Restaurant operators can control the postarrival phase by managing the waiting and seating process. If managed well, customers' waiting time will be brief or at least predictable. Either way, customers feel that they have reasonable control over their dining experience. In addition, tightening the wait time will lead to an increase in transaction convenience.

To achieve those postarrival goals, managers must track when tables become available, specify accurate wait times, notify customers when their table is available, and ensure that guests are seated at the right table. The criteria for the "right table" involve the table that best fits the party, the table that least interferes with seating other parties, the table the customer prefers, or the table in the appropriate server station (McGuire and Kimes 2006). 
Restaurants should be cautious in assigning duties to hosts and hostesses beyond keeping track of tables and arrivals. Such duties as seating, answering the phone, and retrieving takeout orders may not interfere with the job during slow periods, but adding those responsibilities can prove problematic during busy periods if they interfere with seating the right party at the right table at the right time.

If we think of the host or hostess as the restaurant's revenue manager, this raises a concern when that person is not one of the most experienced employees at the restaurant. Lack of experience and knowledge can lead to giving inaccurate wait times, seating people at the wrong table (from a revenue standpoint), and being unsure of how to combine tables most effectively for revenue purposes. Technology can help alleviate this problem by helping hosts and hostesses make the right decisions.

\section{Table Management Systems}

TMSs can help the host or hostess see which tables are available, the stage of the meal for that table, which ones will soon be available, and which can be combined. In addition, TMSs include systems for tracking reservations, walk-ins, and call-ahead parties. Some TMSs develop wait time estimates based on the number of people seated and the number of people waiting (some even track the accuracy of wait time estimates) and suggest the correct table at which to seat the party. TMSs are available from such vendors as Jtech, OpenTable, QSR Automation, and Reserveinteractive.

Beyond managing guest seating, TMSs can help ensure that tables are equitably distributed among servers and can provide management with detailed performance statistics on dining duration, seat occupancy, and wait time forecasting accuracy. TMSs are particularly useful in busy restaurants, especially when the floor layout means that parts of the restaurants are not in clear sight and the host or hostess is relatively inexperienced (Techtonics 2006).

\section{Communication Systems}

Rather than have customers wait in a physical queue, most table service restaurants have customers wait in the bar or a designated seating area. Without an obvious queue, the question becomes one of how to notify customers when their table is ready. Traditionally, the host has to find the customer based on visual recognition. While this provides a personal touch, it can slow the seating process (especially when the host cannot find the guest) and requires the host to leave the stand. Many restaurants can get around this with speaker systems or a paging device (which vibrates or lights up when the table is ready), but none of these systems is appropriate in upscale restaurants.

Two sources of pagers are Long Range Systems and Jtech. Most pagers work as long as the customer is within a certain distance of the restaurant, meaning that customers must wait either at the restaurant or somewhere nearby. To address this problem, cell-phone-based paging systems such as Queuent.com, have been developed. These systems allows the restaurant to call customers when their table is ready, so that customers do not have to remain near the restaurant while waiting. Many of these systems also allow customers to postpone their seating time by a certain number of minutes or notify the restaurant that they have decided to cancel their place in line (i.e., not dine at the restaurant).

\section{Preprocess Stage}

Restaurants have two primary technologies available to help manage the preprocess 
stage: handheld ordering devices and communications systems. This equipment has the potential to speed up the ordering process by relaying orders from the server to the kitchen as they are being taken. Handheld order-taking devices are available from various vendors (including PalmTeq, eWaiter, RCS, and Ingenico) and have been used in a number of European restaurants and in some U.S. concepts, such as Seasons 52. Handheld order-taking technology is designed to reduce order time, to improve customer service by allowing servers to spend more time with guests, and to provide guests with more detailed information on the items that they are ordering. Many restaurant operators and servers have been resistant to handheld order-taking devices because of the cost and the perceived decrease in personal service. To the contrary, if these devices are used to their best advantage, handheld order-taking technology can provide the potential for increased upselling and be used to enhance the guest experience. Regardless of the order-taking approach the key to effective management of this stage is immediately transferring orders to the POS system, so that they are quickly conveyed to the bar and kitchen for preparation. When the order is ready, communications systems such as pagers or headsets can be used to notify servers.

\section{In-Process Stage}

The key to managing the in-process stage is to control the pace at which the meal is prepared and served and to streamline any potential bottlenecks. Once the food is on the table, care must be taken to ensure that guests feel neither rushed nor delayed because of inefficient operations. Restaurants can use kitchen display systems (KDSs), the TMSs described above, and communications and paging devices for best control of the in-process stage pace.
Kitchen display systems. KDSs are used in a number of casual restaurants, including Applebees, Smokey Bones, and Chili's. KDS vendors include Micros, QSR Automation, and Logic Controls. KDSs can be used to help the kitchen better manage orders and to ensure that orders are prepared in a timely fashion. Companies using these systems report a reduction in production time, an increase in kitchen volume, and a reduction in food spoilage. These systems help restaurants develop better control of when to prepare and deliver menu items and help managers increase control of the consistency of both the menu item's preparation and its associated delivery. They can also be used to help develop better detailed menu item forecasts (which in turn can reduce spoilage) and to provide line cooks with training and reminders on how to prepare different menu items. When integrated with a POS system and a TMS, KDSs can also provide better information with which to make wait time estimates (Richardson 2004; Robinson-Jacobs 2004).

Communications systems. Pager and alert systems are equally useful for managers, employees, and guests. These systems can be used to notify servers when a table is seated, when the food and drink orders are ready in the kitchen or bar, or when there are potential problems in the kitchen; to notify managers when there are potential problems in the kitchen or restaurant; and to notify bus staff and hosts when tables are ready to be cleaned and when tables are available to be reseated. This is in addition to allowing guests to page their server when they need additional items or would like to pay the bill (a guest pager system is available from ESP Systems).

Headphone and walkie-talkie systems can work in a casual dining environment but may be seen as inappropriate on the 
restaurant floor in a fine-dining or upscale environment. Pagers (other than for guests) are much less obtrusive and can be used to streamline the guest experience. Communication systems are available from Long Range Systems, Jtech, and Queuent.

\section{Postprocess Stage}

The postprocess stage is a logical point to improve guests' experience by tightening operations. Speeding up the payment process can not only improve customer satisfaction but can also reduce meal duration and allow additional guests to be seated in busy periods (Noone and Kimes 2005; Noone et al. 2007). The TMSs and communications devices discussed above can be useful in the postprocess stage as can handheld credit card processing devices.

European restaurants have used handheld credit card machines for a number of years, but U.S. restaurant operators have been slow to adopt the technology. With handheld machines, customers always have their credit card in sight, and these machines also allow the restaurant operator to speed up the transaction because the server does not have to travel to a far corner of the restaurant to swipe a card. Given the increased attention to credit card security (Sidel 2007; McQueen 2007), it makes sense for restaurants to consider this technology. Devices of this type are available from Verifone, Ingenico, and Hypercom, among others.

\section{Turnover Stage}

Once customers leave the table, anything that can be done to reduce the turnaround time during busy periods can lead to increased revenue (Kimes and Chase
1998; Kimes et al. 1998; Thompson 2008). As I mentioned above, TMSs and communication devices can help notify restaurant staff when guests are near the end of their meal, and communication devices such as pagers and headsets can be used to alert bus staff to clear and reset the table.

\section{Issues to Address}

Even considering the benefits I have discussed, the cost of technology is a major concern. Adding to the monetary cost, implementation of technology and revenue management can result in conflicts for both customers and employees (Wirtz et al. 2003). Unless these conflicts are clearly addressed, most technologybased revenue management efforts will be unsuccessful.

\section{Financial Analysis}

Revenue management technology can be subjected to financial analysis by determining the value of increased business and comparing it to the cost of the technology. While such an approach does not include the intangible benefits of improved customer satisfaction or enhanced customer control, it provides a starting point for assessing the investment.

The analysis starts by tallying the number of hours per week when customers must wait or when reservations must be denied. Next, an operator would collect information on the average number of covers served per hour during those busy periods, the average check per person, and the average table duration (the time between when a party is seated and when the next party is seated). The theoretical annual baseline revenue per busy hour can be calculated using the following formula: 
52 weeks $\times$ (no. of busy hours/week) $\times$ (average no. of covers served/hour) $\times$ (average check per person)

Table duration (in hours)

Say that a 100 -seat restaurant with 10 busy hours per week served an average of 50 covers per hour during busy periods, had an average check per person of $\$ 20$, and had an average meal duration of 60 minutes. Its annual baseline revenue would be

$$
\begin{aligned}
& 52 \text { weeks } \times(10 \text { busy hours/week }) \\
& \times(50 \text { covers served } / \text { hour }) \times(\$ 20) \\
& (60 / 60)
\end{aligned}=\$ 520,000
$$

Assume that the restaurant is considering the adoption of a handheld ordering system that will cost $\$ 10,000$. Management estimates that this system will allow the restaurant to speed up check processing by 3 minutes. If that estimate is correct, and the time saved is filled by additional covers, the restaurant's new annual revenue during busy periods would be

52 weeks $\times(10$ busy hours/week $)$ $\times(50$ covers served/hour $) \times(\$ 20)$ $(55 / 60)$

The annual incremental revenue would be $\$ 27,368$.

Clearly, the entire amount of this revenue would not flow to the bottom line because of the incremental food and labor costs involved. Assume that the restaurant has a flow-through rate of 50 percent (i.e., 50 percent of incremental revenue flows to the bottom line). This would reduce the incremental contribution to $\$ 13,684$. With a cost of $\$ 10,000$ for the technology, this means that the investment would pay for itself in less than nine months $(\$ 10,000 /$ $\$ 13,684=0.73$ years). Provided that the technology decreases denied reservations and seating, similar analyses can be done for other technologies, whether they are aimed at decreasing meal and table duration, increasing incremental business, or increasing the average check. Again, while this sort of analysis does not capture the intangible benefits associated with technology adoption, it can provide a good starting point for analyzing the return on the investment. As pointed out earlier, a simulation of the actual potential revenue increases from a reduced dining duration demonstrates only 25 percent of the theoretical estimates (see Gary Thompson's [2008] article in this issue).

\section{Customer and Employee Issues}

As I said above, adoption of any new technology or revenue management approach results in conflicts for both customers and employees (Wirtz et al. 2003). Unless these conflicts are clearly addressed, the implementation of the technology may not lead to the desired result.

Customer issues. Research on the adoption of customer-service-related technologies has shown that customers embrace technology first and foremost when it actually works (Meuter et al. 2000; Bitner, Ostrom, and Meuter 2002). Utility is key to customer acceptance. Successful technology can (1) help customers out of an awkward situation (i.e., customers can order their food online and pick it up on the way home from work and not have to worry about getting their children out of the car) and (2) save them time and money or provide them with better access to the company (i.e., if the check processing time is reduced or if customers can make reservations whenever they want). On the other hand, customers have no patience for technologies that fail to operate as advertised, that cost them more time, that are poorly designed, or that are not well supported. So not only must one educate customers on how to use the technology, but it is essential that the technology be as foolproof as 
possible. Finally, at the beginning of the implementation, alternatives to the technology should be available for technophobic customers.

Companies adopting technology that will affect customers are advised to do the following (Bitner, Ostrom, and Meuter 2002):

1. Be clear on the strategic purpose of the technology. Understand why the restaurant is adopting the technology, whether to increase revenue, to reduce labor costs, to increase customer satisfaction, to streamline meal preparation and delivery, or to save time.

2. Maintain a customer focus. If the technology is to be successful, operators must concentrate on how guests can benefit from the use of the technology. Will it give customers more control over their experience? Will it increase customer convenience? Will it help the restaurant provide better service?

3. Actively promote the use of the technology and educate customers on how to use it. In most cases, a quick demonstration will suffice to explain how a new device works. Once guests get used to the technology, further demonstrations will be unnecessary; but it is important to provide the necessary support until customers become comfortable with the technology (Ford and Heaton 2001).

4. Prevent and manage failure. Operators should make sure that the system is well tested, that employees are well trained on how to use the system, and that backup or alternative systems are available in case of failure. For example, if the network supporting handheld credit card machines goes down, the restaurant needs to have some sort of backup method of processing payments.

5. Offer choices. Because some customers may prefer not to use the technology, restaurants should provide alternative ways of performing the task, preferably the approach that guests have always used (Ford and Heaton 2001). Even with online reservations, some customers will prefer to call the restaurant. Likewise, some customers may like using a handheld credit card machine because of the increased security, but others may feel uncomfortable with it and may prefer to have the payment processed in the traditional manner.

Employee issues. The two most important factors that affect acceptance of a work-related technology are perceived usefulness and ease of use (Davis 1989; Venkatesh et al. 2003). Perceived usefulness relates to employees' view of how the technology will enhance their job performance. For example, if a server realizes that he or she can make more tips by being able to serve more customers because of a reduction in dining time, he or she is much more likely to be in favor of the technology. Similarly, if hosts and hostesses see that a table management system will allow them to quote a more accurate wait time, they will appreciate the technology because their job will be much more pleasant and guests will be happier.

Perceived ease of use involves employees' assessment of the system's convenience and ease of use. For example, if line cooks find that a kitchen display system makes it easier to track which orders are up or provides information on how to prepare a new menu item, they are more likely to accept such a system. If bussers find that communication systems make it easier to know when tables should be cleaned and reset, they are more likely to want to use those systems.

Note that these aspects of success hinge on employees' perceptions of the technology. Consequently, I suggest that management not only provide technical training on 
how to use the technology but also emphasize its utility and ease of use. In addition, front-of-house employees need to be trained on how to explain the technologies to guests and, when appropriate, provide guidance on how to use the technology.

\section{Conclusion}

Technology can be a valuable adjunct to a restaurant's revenue-management-based drive to achieve greater profitability. Properly implemented, technology will increase customers' perceptions of control and convenience and thereby increase their satisfaction, augmenting the prospect of increased repeat business. Technology can also help the restaurant increase the speed of service (which will result in increased volume during busy periods), reduce labor costs, and attract incremental business.

In this article, I have presented a framework for assessing the impact of technology on table service restaurant revenue. The framework lends itself to a number of different research directions, including

1. the effects of different types of restaurant technology on meal duration and customer throughput in table service restaurants;

2. the effects of different types of restaurant technology on perceived customer control, perceived customer convenience, and customer satisfaction in table service restaurants;

3. case studies on the implementation of different restaurant technologies and their effect on meal duration, customer turnover, and customer satisfaction in table service restaurants;

4. the effect of technology on transaction duration and revenue in quickservice restaurants; and

5. case studies on the implementation of different restaurant technologies and their effect on meal duration, transaction speed, and customer satisfaction in quick-service restaurants.

As with any operational improvement, the costs associated with technology adoption must be balanced with the potential benefits. In addition, the effects on customer and employee satisfaction must be carefully assessed. That said, the revenue potential associated with the appropriate adoption of technology is considerable.

\section{References}

Anonymous. 2006. More US restaurants using online reservations. AllBusiness, July 31, 2006. http://www.allbusiness.com/agriculture-forestryfishing/4437517-1.html.

Averill, James R. 1973. Personal control over aversive stimuli and its relationship to stress. Psychological Bulletin 80 (4): 286-303.

Berry, Leonard L., Kathleen Seiders, and Dhruv Grewal. 2002. Understanding service convenience. Journal of Marketing 66 (3): 1-17.

Bitner, Mary Jo, Amy L. Ostrom, and Matthew L. Meuter. 2002. Implementing successful self-service technologies. Academy of Management Executive 16 (4): 96-109.

Carroll, William J., and Richard C. Grimes. 1995. Evolutionary change in product management: Experiences in the car rental industry. Interfaces 25 (5): 84-104.

Davis, Fred D. 1989. Perceived usefulness, perceived ease of use, and user acceptance of information technology. MIS Quarterly 13 (3): 319-40.

Ford, Robert C., and Cherrill P. Heaton. 2001. Managing your guest as a quasi-employee. Cornell Hotel and Restaurant Administration Quarterly 42 (2): 46-55.

Hanks, Richard B., R. Paul Noland, and Robert G. Cross. 1992. Discounting in the hotel industry, a new approach. Cornell Hotel and Restaurant Administration Quarterly 33 (3): 40-45.

Hellmich, Nanci. 2005. Takeout, curbside dining are on the rise. USA Today, October 3, 2005. http://usatoday.com/news/health/2005-10-03-diningcars_x.htm.

Hui, Michael K., and John E. G. Bateson. 1991. Perceived control and the effects of crowding and consumer choice on the service experience. Journal of Consumer Research 18 (September): 174-84.

Hui, Michael K., and David K. Tse. 1996. What to tell consumers in waits of different lengths: An integrative model of service evaluation. Journal of Marketing 60 (April): 81-90.

Kimes, Sheryl E. 2004a. Restaurant revenue management. Center for Hospitality Research Report. Ithaca, NY: Cornell University Press.

. 2004b. Restaurant revenue management: Implementation at Chevys Arrowhead. Cornell Hotel and Restaurant Administration Quarterly 43 (4): 48-57. 
Kimes, Sheryl E., and Richard B. Chase. 1998. The strategic levers of yield management. Journal of Service Research 1 (2): 156-66.

Kimes, Sheryl E., Richard B. Chase, Sunmee Choi, Elizabeth N. Ngonzi, and Philip Y. Lee. 1998. Restaurant revenue management. Cornell Hotel and Restaurant Administration Quarterly 40 (3): 40-45.

Kimes, Sheryl E., and Gary M. Thompson. 2004. Restaurant revenue management at Chevys: Determining the best table mix. Decision Sciences 35 (3): 371-91.

. 2005. An evaluation of heuristic methods for determining the best table mix in full-service restaurants. Journal of Operations Management 23 (6): 599-617.

Kimes, Sheryl E., and Jochen Wirtz. 2007. Customer satisfaction with seating policies in casual-dining restaurants. Center for Hospitality Research Report. Ithaca, NY: Cornell University Press.

Kimes, Sheryl E., Jochen Wirtz, and Breffni M. Noone. 2002. How long should dinner take? Measuring expected meal duration for restaurant revenue management. Journal of Revenue and Pricing Management 1 (3): 220-33.

Krummert, Bob. 2003. Rush hour. Restaurant Hospitality, July, pp. 43-48.

Lang, Joan. 2006. Is the web really a sales builder? Restaurant Business, May, pp. 11-12.

Langer, Ellen J. 1983. The psychology of control. Beverly Hills, CA: Sage.

Layton, Thomas. 2006. The Internet is changing dining out behavior. Are you ready? Savoir Fare, February, p. 1. http://otrestaurant.com/.

McGuire, Kelly A., and Sheryl E. Kimes. 2006. The perceived fairness of waitlist-management techniques for restaurants. Cornell Hotel and Restaurant Administration Quarterly 47 (2): 121-34.

McQueen, M. P. 2007. How to protect your plastic; recent thefts of credit- and debit-card information highlight need for consumer caution; beware of unbranded ATMs. Wall Street Journal, March 15, 2007, p. D1.

Meuter, Matthew L., Amy L. Ostrom, Robert I. Roundtree, and Mary Jo Bitner. 2000. Self-service technologies: Understanding customer satisfaction with technology-based service encounters. Journal of Marketing 64 (3): 50-64.

Noone, Breffni M., and Sheryl E. Kimes. 2005. Dining duration and customer satisfaction. Center for Hospitality Research Report. Ithaca, NY: Cornell University Press.

Noone, Breffni, Sheryl E. Kimes, Anna Mattila, and Jochen Wirtz. 2007. The effect of meal pace on customer satisfaction. Cornell Hotel and Restaurant Administration Quarterly 48 (3): 231-45.
Prewitt, Milford. 2005. Operators see pros, cons in online reservations boom. Nation's Restaurant News, February 28, 2005. http://findarticles.com/p/articles/ mi_m3190/is_9_39/ai_n12934951.

Richardson, Nicole M. 2004. Kitchen confidence. Hospitality Technology, October, pp. 23-26. htmagazine.com.

Robinson-Jacobs, Karen. 2004. Nobody screams in a cyber kitchen: Chili's adds computers to better coordinate food service. Dallas Daily News, February 22, 2004. http://qsrautomation.com/PDF/QSR_Cooks_Up_Succ ess.pdf.

Ross, Julie Ritzer. 2006. Online reservations technology gains ground. Nation's Restaurant News, June 26, 2006, p. 68.

Rust, Roland T., Anthony J. Zahorik, and Timothy L. Keiningham. 1995. Return on quality (ROQ): Making service quality financially accountable. Journal of Marketing 59 (2): 58-70.

Sidel, Robin. 2007. In data leaks, culprits are often mom, pop; credit-card industry tries to add safeguards; honest errors occur. Wall Street Journal, September 22, 2007, p. B1.

Smith, Barry A., John F. Leimkuhler, and Ross M. Darrow. 1992. Yield management at American Airlines. Interfaces 22 (1): 8-31.

Techtonics. 2006. Tapping table management: Exclusive survey reveals qualities most desired in a table management system. Hospitality Technology. http://www.qsrautomation.com/PDF/HT_Techtonics _TableMgt_Spt06.pdf.

Thompson, Gary. 2008. Revenue benefits of reducing dining duration in restaurants. Cornell Hospitality Quarterly

Venkatesh, Viswanath, Michael G. Morris, Gordon B. Davis, and Fred D. Davis. 2003. User acceptance of information technology: Toward a unified view. MIS Quarterly 27 (3): 425-78.

Warner, Melanie. 2006. Fed up with fast food, Americans turn to "curbside" takeout. New York Times, June 6, 2006.

Webb, Wendy. 2006. Online ordering: Web sites eliminate the wait. Franchise Times, May, p. 36.

Wirtz, Jochen, Sheryl E. Kimes, Jeannette Ho Pheng Theng, and Paul Patterson. 2003. Revenue management: Resolving potential customer conflicts. Journal of Revenue and Pricing Management 2 (3): 216-28.

Sheryl E. Kimes, Ph.D. is Singapore Tourism Board Distinguished Professor in Asian Hospitality Management and professor of operations management at the Cornell University School of Hotel Administration (sek6@cornell.edu). 